\title{
MACROSCOPIC CROSS SECTIONS GENERATION BY MONTE CARLO CODE MCS FOR FAST REACTOR ANALYSIS
}

\author{
Tung Dong Cao Nguyen, Hyunsuk Lee, Xianan Du, Vutheam Dos, Tuan Quoc Tran and \\ Deokjung Lee
}

\author{
Ulsan National Institute of Science and Technology (UNIST)
}

50 UNIST-gil, Ulsan 44919, Republic of Korea

tungnguyen@unist.ac.kr, hyunsuklee@unist.ac.kr,dxndxnwww@unist.ac.kr, dosvutheam8@unist.ac.kr, trantuan@unist.ac.kr, deokjung@unist.ac.kr

\begin{abstract}
Recent researches have become more interested in the feasibility of using Monte Carlo (MC) code to generate multi-group (MG) cross sections (XSs) for fast reactor analysis using nodal diffusion codes. The current study, therefore, presents a brief methodology for MG XSs generation by the in-house UNIST MC code MCS, which can be compatibly utilized in nodal diffusion codes, PARCS and RAST-K. The applicability of the methodology is quantified on the sodium fast reactor (SFR) ABR-1000 design with a metallic fuel from the OECD/NEA SRF benchmark. The few-group XSs generated by MCS with a two-dimensional (2D) fuel assembly geometry are well consistent with those of SERPENT 2. Furthermore, the simulation of beginning-of-cycle (BOC) steady-state three-dimensional (3D) whole-core problem with PARCS and RAST-K is conducted using the generated 24-group XSs by MCS. The nodal diffusion solutions, including the core $k_{\text {eff, }}$ power profiles and various of reactivity parameters, are compared to reference whole-core results obtained by MC code MCS. Overall, the codeto-code comparison indicates a reasonable agreement between deterministic and stochastic codes, with the difference in $k_{\text {eff }}$ less than $100 \mathrm{pcm}$ and the root-mean-square (RMS) error in assembly power less than $1.15 \%$. Therefore, it is successfully demonstrated that the employment of the MG XSs generation by MCS for nodal diffusion codes is feasible to accurately perform analyses for fast reactors.
\end{abstract}

KEYWORDS: Monte Carlo, multi-group cross section, fast reactor, MCS, nodal diffusion.

\section{INTRODUCTION}

In general, a Monte Carlo (MC) code or a deterministic code is to be employed to simulate the nuclear reactor. The main advantages of MC codes are in the accuracy in geometry simulation and neutron interactions. However, those are counterweighted with the high computational cost due to a complex and detail level of a certain model. On the other hand, deterministic code's capability is to provide an adequately accurate result, which requires less computational demand. Nevertheless, their disadvantage is the simplicity in geometry and transport/diffusion physics. Recently, the combination of both stochastic and deterministic codes has become more and more attractive in the framework of establishing the basic viability of the advanced fast reactor. This approach ensures the superposition of the benefits of these methods. The major purpose of a code system is to achieve accurate evaluation and analysis in a systematic manner for a wide variety of fast reactor. Therefore, current research is focused on the use of both MC and 
deterministic codes for 3D fast reactor simulation and analysis. In this work, the generation of the multigroup (MG) cross sections (XSs) data by MC method is implemented in the in-house UNIST MC code MCS. These XSs data is then converted into the compatible database that is able to be used in nodal diffusion codes PARCS and RAST-K. The simulation of beginning-of-cycle (BOC) steady-state threedimensional (3D) whole-core problem, including the core $k_{\text {eff, }}$ power profiles and various of reactivity parameters, are compared to reference whole-core results obtained by MC code MCS.

\section{COMPUTER CODES}

\subsection{UNIST Monte Carlo code MCS}

MCS is a 3D continuous-energy neutron-physics code for particle transport based on the MC method, under development at UNIST since 2013 [1-2]. MCS can conduct criticality runs for reactivity calculations and fixed-source runs for shielding problems. MCS has been designed from scratch since 2013 to conduct whole-core criticality simulation with pin-wise depletion and thermal/hydraulic feedback. MCS neutron transport capability is verified and validated against several benchmark problems, including the BEAVRS benchmark, $\sim 300$ cases from the International Criticality Safety Benchmark Experimental Problem (ICSBEP) and the Jordan Research and Training Reactor (JRTR). Recently, the MG XSs generation has been implemented in MCS.

\subsection{SERPENT 2}

The SERPENT MC code [3] is a continuous energy MC reactor physics burnup code with recent applications in radiation shielding, multi-physics, and fusion neutronics. It is currently employed for reactor physics applications, including homogenized group constant generation, burnup calculations, the modeling of small research reactor cores and multi-physics calculations. SERPENT has been developed at VTT Technical Research Centre of Finland since 2004 and the current development version, SERPENT 2, has notably diversified the applications of the code.

\subsection{RAST-K and PARCS}

The RAST-K (R2) code has been developed at UNIST for diffusion core calculations [3]. It adopts the 3D MG nodal method with multi-group coarse mesh finite difference (CMFD) acceleration technique to solve steady state and transient problems with assembly-level nodes. Recently, the triangular polynomial expansion nodal (TPEN) method has been implemented in RAST-K for fast reactor analysis. PARCS is a 3D reactor core simulator, which solves the steady-state and time-dependent, MG neutron diffusion and SP3 transport equations in square and hexagonal geometries [4].

\section{MULTI-GROUP CROSS SECTIONS GENERATION WITH MONTE CARLO METHOD}

A general goal of the $\mathrm{MC}$ code is to estimate the average neutron flux for a certain geometrical region and for a number of energy ranges (energy group) [5]:

$$
\phi_{g}=\frac{1}{V} \int_{V} \int_{E_{g}}^{E_{g-1}} \phi(r, E) d E d V,
$$

where $\phi(r, E)$ is the space and energy dependent flux, $V$ is volume for averaging flux region, and $g$ is group index. From this, the specific reaction rates can be obtained by multiplying flux estimates by an interest XS: 


$$
R_{x}=\frac{1}{V} \int_{V} \int_{E_{g}}^{E_{g-1}} \Sigma_{x}(r, E) \phi(r, E) d E d V,
$$

Division of these two quantities gives the MG XS for a certain reaction type $\mathrm{x}$ and energy group $g$ :

$$
\Sigma_{x, g}=R_{x} / \phi_{g}{ }^{\prime}
$$

As discussed, the generated XSs are to be utilized in MG nodal diffusion code, the required data are therefore the total XS, the absorption XS, the fission and fission production XS, fission spectrum, scattering matrix and transport XS. It is noted that the Pn scattering matrix in this study is only weighted by the scalar flux:

$$
\Sigma_{s, g \rightarrow g^{\prime}}=\left(\frac{1}{V} \int_{V} \int_{E_{g}}^{E_{g^{\prime}}} \Sigma_{s}^{l}\left(r, E \rightarrow E^{\prime}\right) \phi(r, E) d E d V\right) / \phi_{g},
$$

where $=$ scattering order, which is also the 1 th order Legendre polynomial coefficient. The transport XS is estimated by using the outer-scatter approximation with $G$ is the total number of groups:

$$
\Sigma_{t r, g}=\Sigma_{t, g}-\sum_{g^{\prime}=1}^{G} \Sigma_{s, g \rightarrow g^{\prime}}^{1}
$$

\section{NUMERICAL RESULTS}

First, the XS set for 4-group energy structure and for a 2D assembly problem is generated by MCS and compared to those of SERPENT 2. Then, the XS set for 24-group energy structure [7] is obtained by MCS and converted into a compatible database that can be used in the nodal diffusion codes for the fast reactor 3D core problem. The two energy structures are listed in Tables I and II. The ENDF/B-VII.0 library is used, where the fuel and other material temperature is set $900 \mathrm{~K}$ and $600 \mathrm{~K}$, respectively.

Table I. 4-group energy structure.

\begin{tabular}{|c|c|c|}
\hline No. & Upper E (MeV) & Lower E (MeV) \\
\hline 1 & $1.41910 \mathrm{E}+01$ & $1.11090 \mathrm{E}-01$ \\
\hline 2 & $1.11090 \mathrm{E}-01$ & $1.72230 \mathrm{E}-03$ \\
\hline 3 & $1.72230 \mathrm{E}-03$ & $2.67030 \mathrm{E}-05$ \\
\hline 4 & $2.67030 \mathrm{E}-05$ & $1.00000 \mathrm{E}-11$ \\
\hline
\end{tabular}

Table II. 24-group energy structure.

\begin{tabular}{|c|c|c|c|c|c|c|c|c|}
\hline No. & $\begin{array}{c}\text { Upper E } \\
(\mathrm{MeV})\end{array}$ & $\begin{array}{c}\text { Lower E } \\
(\mathrm{MeV})\end{array}$ & No. & $\begin{array}{c}\text { Upper E } \\
(\mathrm{MeV})\end{array}$ & $\begin{array}{c}\text { Lower E } \\
(\mathrm{MeV})\end{array}$ & No. & $\begin{array}{c}\text { Upper E } \\
(\mathrm{MeV})\end{array}$ & $\begin{array}{c}\text { Lower E } \\
(\mathrm{MeV})\end{array}$ \\
\hline 1 & $1.96403 \mathrm{E}+01$ & $1.00000 \mathrm{E}+01$ & 9 & $3.01974 \mathrm{E}-01$ & $1.83156 \mathrm{E}-01$ & 17 & $5.53084 \mathrm{E}-03$ & $3.35463 \mathrm{E}-03$ \\
\hline 2 & $1.00000 \mathrm{E}+01$ & $6.06531 \mathrm{E}+00$ & 10 & $1.83156 \mathrm{E}-01$ & $1.11090 \mathrm{E}-01$ & 18 & $3.35463 \mathrm{E}-03$ & $2.03468 \mathrm{E}-03$ \\
\hline 3 & $6.06531 \mathrm{E}+00$ & $3.67879 \mathrm{E}+00$ & 11 & $1.11090 \mathrm{E}-01$ & $6.73795 \mathrm{E}-02$ & 19 & $2.03468 \mathrm{E}-03$ & $1.23410 \mathrm{E}-03$ \\
\hline 4 & $3.67879 \mathrm{E}+00$ & $2.23130 \mathrm{E}+00$ & 12 & $6.73795 \mathrm{E}-02$ & $4.08677 \mathrm{E}-02$ & 20 & $1.23410 \mathrm{E}-03$ & $7.48518 \mathrm{E}-04$ \\
\hline 5 & $2.23130 \mathrm{E}+00$ & $1.35335 \mathrm{E}+00$ & 13 & $4.08677 \mathrm{E}-02$ & $2.47875 \mathrm{E}-02$ & 21 & $7.48518 \mathrm{E}-04$ & $4.53999 \mathrm{E}-04$ \\
\hline 6 & $1.35335 \mathrm{E}+00$ & $8.20850 \mathrm{E}-01$ & 14 & $2.47875 \mathrm{E}-02$ & $1.50344 \mathrm{E}-02$ & 22 & $4.53999 \mathrm{E}-04$ & $3.04325 \mathrm{E}-04$ \\
\hline 7 & $8.20850 \mathrm{E}-01$ & $4.97871 \mathrm{E}-01$ & 15 & $1.50344 \mathrm{E}-02$ & $9.11882 \mathrm{E}-03$ & 23 & $3.04325 \mathrm{E}-04$ & $1.48625 \mathrm{E}-04$ \\
\hline 8 & $4.97871 \mathrm{E}-01$ & $3.01974 \mathrm{E}-01$ & 16 & $9.11882 \mathrm{E}-03$ & $5.53084 \mathrm{E}-03$ & 24 & $1.48625 \mathrm{E}-04$ & $1.00001 \mathrm{E}-11$ \\
\hline
\end{tabular}




\subsection{Multi-group cross section comparison between MCS and SERPENT 2}

Since the original aim of this work is to serve in the fast reactor analysis and development, the fuel subassembly of a typical sodium fast reactor, ABR-1000 [6], is employed in this analysis. Figure 1 illustrates the 2D layout of the ABR-1000 sub-assembly [6]. Table III summarizes the 4-group flux and macro XSs generated by MCS compared to those of SERPENT 2. It is seen that MCS solution is well agreed with SERPENT 2 solution, and it also notice that the considered error at group 4 is due to the poor uncertainties as lack of neutrons in the small energy ranges. Figures 2 and 3 show the P0 and P1 scattering errors and their uncertainties (in \%) between MCS and SERPENT 2. The index in the green row stands for the departure energy group, while the vertical orange column indicates the arrival energy group. All the groupwise scattering XSs by MCS are well consistent with those of SERPENT 2, except group 4 because of the lack of neutron in the thermal energy range of a fast reactor assembly.

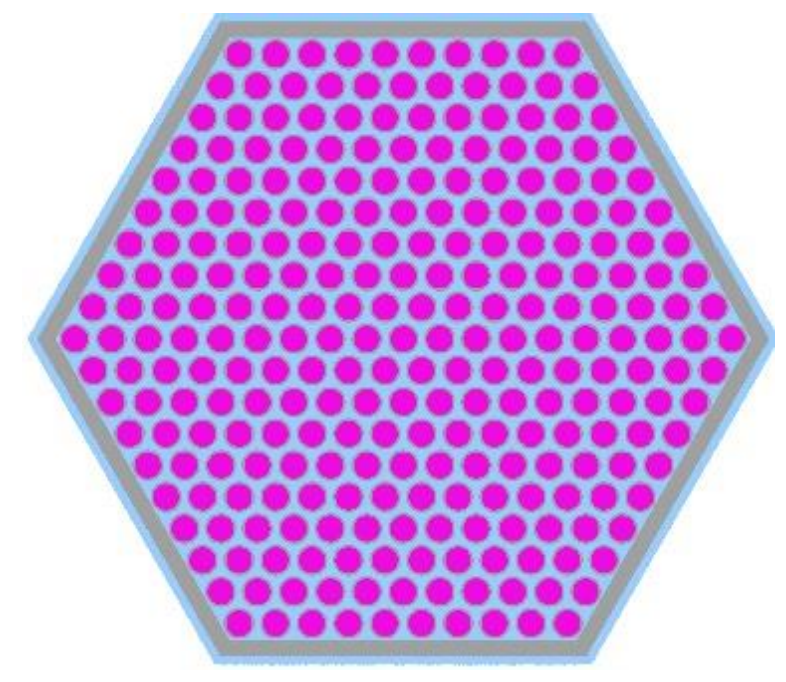

Figure 1. ABR-1000 Fuel Sub-Assembly Geometry [6].

Table III. Summary of 4-group flux and macro XSs (in: $\mathrm{cm}^{-1}$ ).

\begin{tabular}{|c|c|c|c|c|c|c|c|c|c|c|c|}
\hline \multirow[t]{2}{*}{ Parameter } & \multirow[t]{2}{*}{ G } & \multicolumn{2}{|c|}{ MCS } & \multicolumn{2}{|c|}{$\begin{array}{c}\text { Diff. vs. } \\
\text { SERPENT } 2(\%)\end{array}$} & \multirow[t]{2}{*}{ Parameter } & \multirow[t]{2}{*}{ G } & \multicolumn{2}{|c|}{ MCS } & \multicolumn{2}{|c|}{$\begin{array}{c}\text { Diff. vs. } \\
\text { SERPENT } 2(\%)\end{array}$} \\
\hline & & Value & SD (\%) & Value & SD & & & Value & SD (\%) & Value & SD \\
\hline \multirow{4}{*}{ Flux } & 1 & $1.18 \mathrm{E}+02$ & $7.46 \mathrm{E}-03$ & 0.22 & 0.01 & \multirow{4}{*}{$\mathbf{N S F}^{\mathbf{b}}$} & 1 & $8.79 \mathrm{E}-03$ & $5.06 \mathrm{E}-03$ & 0.01 & 0.01 \\
\hline & 2 & $6.53 \mathrm{E}+01$ & $1.08 \mathrm{E}-02$ & 0.21 & 0.01 & & 2 & $6.62 \mathrm{E}-03$ & $2.05 \mathrm{E}-03$ & 0.02 & 0.01 \\
\hline & 3 & $1.12 \mathrm{E}+00$ & $7.46 \mathrm{E}-02$ & 0.29 & 0.11 & & 3 & $2.13 \mathrm{E}-02$ & $2.64 \mathrm{E}-02$ & -0.07 & 0.06 \\
\hline & 4 & $3.03 \mathrm{E}-06$ & $2.74 \mathrm{E}+01$ & -11.31 & 45.63 & & 4 & $3.29 \mathrm{E}-02$ & $5.92 \mathrm{E}+01$ & -91.47 & 64.77 \\
\hline \multirow{4}{*}{ Total } & 1 & $2.08 \mathrm{E}-01$ & $1.21 \mathrm{E}-03$ & 0.00 & 0.00 & \multirow{4}{*}{$\mathrm{Chi}^{\mathrm{c}}$} & 1 & $9.85 \mathrm{E}-01$ & $1.90 \mathrm{E}-03$ & 0.00 & 0.00 \\
\hline & 2 & $3.02 \mathrm{E}-01$ & $2.11 \mathrm{E}-03$ & 0.02 & 0.00 & & 2 & $1.46 \mathrm{E}-02$ & $1.28 \mathrm{E}-01$ & 0.24 & 0.18 \\
\hline & 3 & $3.91 \mathrm{E}-01$ & $6.40 \mathrm{E}-03$ & -0.01 & 0.02 & & 3 & $2.87 \mathrm{E}-05$ & $3.04 \mathrm{E}+00$ & -0.09 & 4.30 \\
\hline & 4 & $5.51 \mathrm{E}-02$ & $2.34 \mathrm{E}+01$ & -93.11 & 24.38 & & 4 & $5.01 \mathrm{E}-08$ & $7.06 \mathrm{E}+01$ & -44.60 & 97.40 \\
\hline \multirow{4}{*}{$\mathbf{A b s}^{\mathrm{a}}$} & 1 & $4.39 \mathrm{E}-03$ & $2.95 \mathrm{E}-03$ & 0.02 & 0.01 & \multirow{4}{*}{ Transport } & 1 & $1.71 \mathrm{E}-01$ & $2.72 \mathrm{E}-03$ & 0.01 & 0.00 \\
\hline & 2 & $6.93 \mathrm{E}-03$ & $3.85 \mathrm{E}-03$ & 0.02 & 0.01 & & 2 & $2.89 \mathrm{E}-01$ & $2.73 \mathrm{E}-03$ & 0.02 & 0.00 \\
\hline & 3 & $2.67 \mathrm{E}-02$ & $2.50 \mathrm{E}-02$ & -0.03 & 0.05 & & 3 & $3.87 \mathrm{E}-01$ & $1.00 \mathrm{E}-02$ & -0.01 & 0.02 \\
\hline & 4 & $2.51 \mathrm{E}-02$ & $3.90 \mathrm{E}+01$ & -90.54 & 44.04 & & 4 & $2.21 \mathrm{E}-02$ & $2.24 \mathrm{E}+01$ & -97.33 & 25.31 \\
\hline
\end{tabular}

${ }^{\mathrm{a}}$ Absorption, ${ }^{\mathrm{b}}$ Fission production, ${ }^{\mathrm{c}}$ Fission spectrum 


\begin{tabular}{|c|c|c|c|c|c|c|c|c|c|}
\hline Error (\%) & $\mathbf{1}$ & $\mathbf{2}$ & $\mathbf{3}$ & $\mathbf{4}$ & $\mathbf{S D}(\mathbf{\%})$ & $\mathbf{1}$ & $\mathbf{2}$ & $\mathbf{3}$ & $\mathbf{4}$ \\
\hline $\mathbf{1}$ & 0.01 & -- & -- & -- & $\mathbf{1}$ & 0.00 & -- & -- & -- \\
\hline $\mathbf{2}$ & 0.05 & 0.02 & -- & -- & $\mathbf{2}$ & 0.02 & 0.00 & -- & - \\
\hline $\mathbf{3}$ & -2.65 & 0.14 & -0.02 & -- & $\mathbf{3}$ & 3.07 & 0.09 & 0.03 & -- \\
\hline $\mathbf{4}$ & -62.01 & 152.98 & 26.76 & -95.27 & $\mathbf{4}$ & 62.96 & 75.01 & 51.58 & 28.60 \\
\hline
\end{tabular}

Figure 2. P0 Scattering Matrix Error, MCS vs. SERPENT 2.

\begin{tabular}{|c|c|c|c|c|c|c|c|c|c|}
\hline Error (\%) & $\mathbf{1}$ & $\mathbf{2}$ & $\mathbf{3}$ & $\mathbf{4}$ & SD (\%) & $\mathbf{1}$ & $\mathbf{2}$ & $\mathbf{3}$ & $\mathbf{4}$ \\
\hline $\mathbf{1}$ & -0.01 & -- & -- & -- & $\mathbf{1}$ & 0.02 & -- & -- & -- \\
\hline $\mathbf{2}$ & 0.01 & 0.02 & -- & -- & $\mathbf{2}$ & 0.09 & 0.05 & -- & -- \\
\hline $\mathbf{3}$ & 14.05 & 0.11 & -0.44 & -- & $\mathbf{3}$ & 23.63 & 0.19 & 1.26 & -- \\
\hline $\mathbf{4}$ & -117.12 & -101.91 & 214.67 & -103.86 & $\mathbf{4}$ & 115.76 & 5681.69 & 107.31 & 166.93 \\
\hline
\end{tabular}

Figure 3. P1 Scattering Matrix Error, MCS vs. SERPENT 2.

\subsection{ARB-1000 analysis by MCS/R2 and MCS/PARCS}

The radial and axial core layouts of the ABR-1000 are shown in Figures 4 and 5 [6]. XSs for fuel subassemblies are generated using a single 2D model of a fuel sub-assembly with reflective boundary conditions, as in Figure 1. All MG XSs for non-multiplying regions are generated using 2D super-cell models as shown in Figure 6 [7]. Those regions are located at the center of the model and surrounded by fuel assemblies to approximate the flux that those experience in a core. The $k_{\text {eff }}$ for $3 \mathrm{D}$ core calculation at beginning-of-cycle (BOC) all rod out (ARO) by MCS/R2, MCS/PARCS, and MCS is summarized in Table IV. The radial assembly-wise power distributions by MCS/PARCS and MCS are shown in Figure 7. It is clearly seen that a great agreement is achieved due to the difference in $k_{\text {eff }}$ less than $100 \mathrm{pcm}$ and the rootmean-square (RMS) in power error is less than $1.15 \%$ and the maximum error is less than $2.5 \%$ for radial power and $4.73 \%$ for axial power. The fuel temperature coefficient (FTC), sodium void worth (SVW) and control rod worth as all rods in (ARI) are also obtained by R2 and PARCS. The comparison of those results with MCS is also shown in Table IV. The FTC and SVW by R2 and PARCS are well agreed with MCS results, except the control rod worth. The rod worth difference is around 2,100 $\mathrm{pcm}(10 \%)$. To achieve the higher accuracy result, the super homogenization method (SPH) should be applied for the XS of the control rods and the neighbor fuel assemblies.

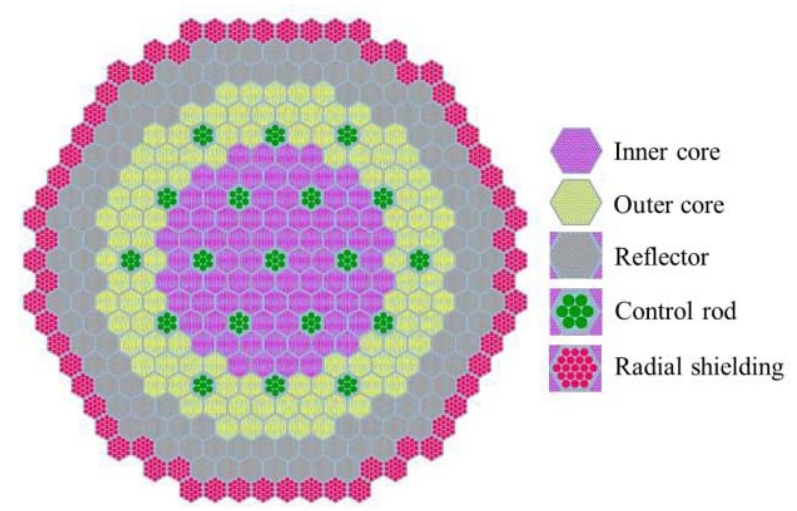

Figure 4. ABR-1000 Radial Core Layout [6]. 


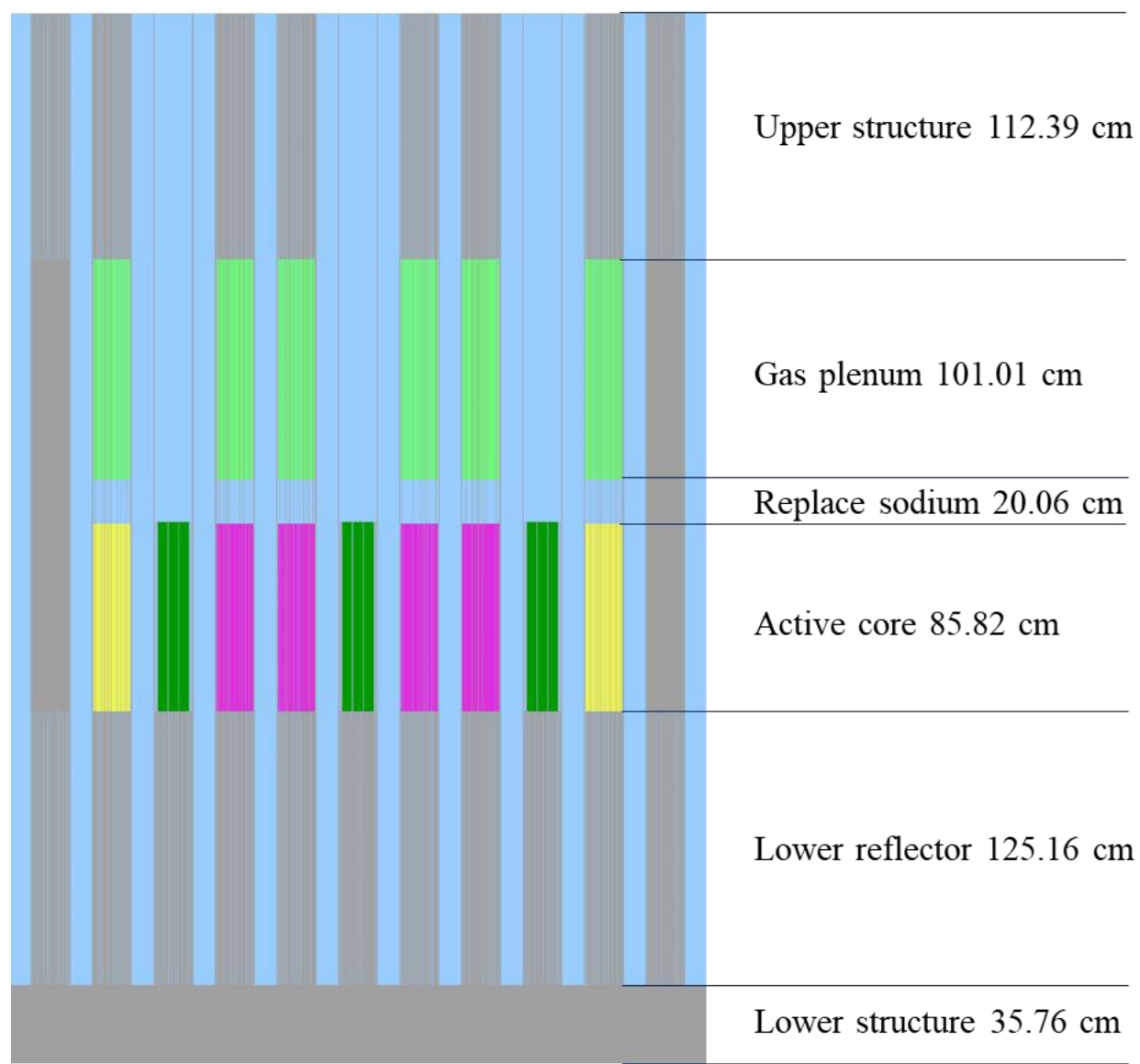

Figure 5. ABR-1000 Axial Core Layout [6].
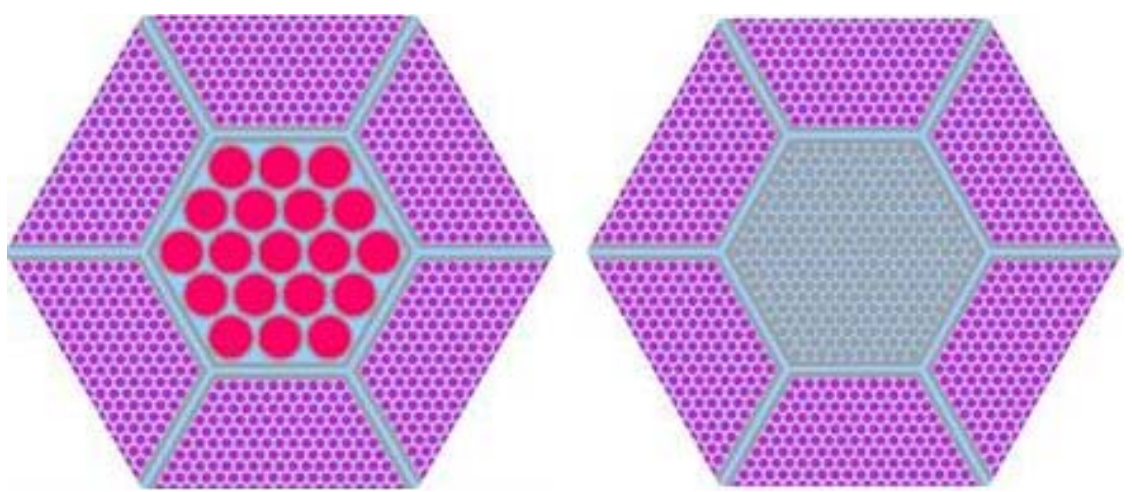

Figure 6. Example for Super-cell Models. 
Table IV. Summary of $k_{\text {eff, }}$ MCS/R2, MCS/PARCS and MCS.

\begin{tabular}{|l|c|c|c|c|c|}
\hline \multicolumn{1}{|c|}{ Code } & MCS & MCS/R2 & Diff. & MCS/PARCS & Diff. \\
\hline Base & $1.03011 \pm 0.00011$ & 1.03121 & 109 & 1.03104 & 93 \\
\hline Fuel: & & & & & \\
- $k_{\text {eff }}$ at $1500 \mathrm{~K}$ & $1.02779 \pm 0.00010$ & 1.02894 & 115 & 1.02894 & 115 \\
- FTC, pcm/K & $-0.365 \pm 0.025$ & -0.355 & 0.010 & -0.330 & 0.035 \\
\hline Sodium void: & & & & & \\
- $k_{\text {eff }}$ & $1.05166 \pm 0.00012$ & 1.05011 & -155 & 1.05011 & -155 \\
- SVR, pcm & $1,989 \pm 16$ & 1,746 & -243 & 1,762 & -228 \\
\hline ARI: & & & & & \\
- $k_{\text {eff }}$ & $0.86645 \pm 11$ & 0.85130 & -1515 & 0.85131 & -1514 \\
- Rod worth, pcm & $18,337 \pm 16$ & 20,494 & 2,157 & 20,476 & 2,139 \\
\hline
\end{tabular}
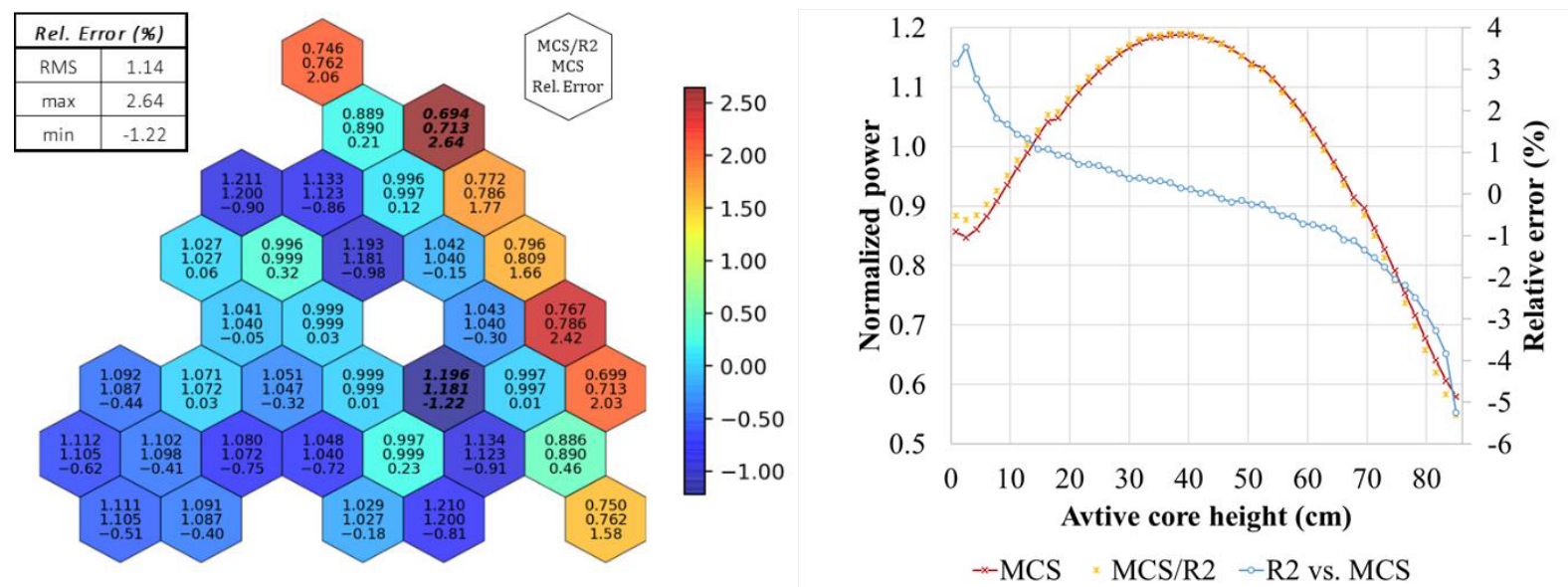

Figure 7. Normalized assembly radial and axial power distribution, MCS/R2 vs MCS.

\section{CONCLUSIONS}

In this study, the feasibility of using the MCS MC code for generating MG XSs at BOC for fast spectrum 3D simulation with the R2 and PARCS simulators is investigated. The 4-group XSs by MCS are compared with SERPENT 2 results, and a great agreement is achieved. The final step is to perform steady-state analysis with PARCS using the 24-group XS data generated by MCS and conduct a comparison in $k_{\text {eff, }}$, power distributions, control rod worth and reactivity coefficients. Results point out a reasonable consistency, mainly explained by the difference between deterministic and stochastic code. The outcome of this study proves the MCS can be a promising tool for MG XSs generation for fast reactor analysis. The future work is focused on the SPH method for the XS of the control rods and the neighbor fuel assemblies, the application of MCS for temperature dependent and coolant density dependent MG XSs for thermalhydraulics feedback for fast reactor.

\section{ACKNOWLEDGMENTS}

This work was supported by the National Research Foundation of Korea (NRF) grant funded by the Korea government (MSIT). (No.NRF-2017M2A8A2018595) 


\section{REFERENCES}

1. Lee H et al., "MCS - A Monte Carlo Particle Transport Code for Large-scale Power Reactor Analysis," Annuals of Nuclear Energy (2019). (Under review)

2. Leppänen J et al., "The Serpent Monte Carlo Code: Status, Development and Applications in 2013," Annals of Nuclear Energy, 82, 142-150 (2015).

3. Choe $\mathrm{J}$ et al., "Verification and validation of STREAM/RAST-K for PWR analysis," Nuclear Engineering and Technology, 51(2), 356-368 (2019).

4. Downar T, "PARCS v2.7 U.S. NRC Core Neutronics Simulator USER MANUAL," U.S. NRC (2006).

5. Hoogenboom J et al., "Generation of Multi-group Cross Sections and Scattering Matrices with the Monte Carlo Code MCNP5," Proc. Joint International Topical Meeting on Mathematics \& Computation and Supercomputing in Nuclear Applications, Monterey, California, April 15-19, p.15-19 (2007).

6. Bernnat W et al., "Benchmark for Neutronic Analysis of Sodium-Cooled Fast Reactor Cores with Various Fuel Types and Core Sizes," Nuclear Energy Agency Technical Report, NEA/NSC (2015).

7. Pereira $G$ et al., "Applying the Serpent-DYN3D Code Sequence for the Decay Heat Analysis of Metallic Fuel Sodium Fast Reactor," Annals of Nuclear Energy, 125, 291-306 (2019). 